\title{
Bruno Olivier
}

Catedrático de Ciências da Informação e da Comunicação. Universidade das Antilhas e da Guiana (French West Indies University)

\section{SISTEMAS EDUCATIVOS ENTRE MÁQUINAS E REDES ${ }^{1}$}

Ideologia tecnicista compõe a base do pensamento da elite dominante para a educação

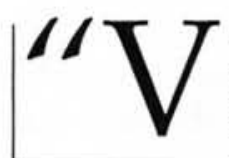

amos nos submergir em um mundo que se banha na informação"2.

"A sociedade de amanhã será um capitalismo sem friç̧ões" ${ }^{\text {. }}$. "O desenvolvimento técnico (...) não está sempre a serviço dos homens. Em particular porque acentua a fragilidade dos sistemas sociais.

As crises das bolsas, financeiras, políticas, que estalam de um extremo a outro do planeta, desestabilizam mais rapidamente ainda as economias, põem à prova a solidariedade e enfraquecem as instituições internacionais. A comunicação triunfante, por mais que reduza o mundo a uma pequena aldeia, nem por isso o tornará mais seguro" 4 .

Os discursos atuais da imprensa, dos industriais, da publicidade e dos meios de massa, de numerosos políticos e responsáveis pela educação e pela formação sobre a "sociedade da informação", sobre o advento da "aldeia global" e o desenvolvimento das redes nos mostram como o discurso utópico deste começo do século XXI é um discurso fundado na dimensão técnica ${ }^{5}$. O determinismo técnico que supostamente deve aportar soluções aos diversos problemas que afetam as nossas sociedades substituiu o determinismo religioso de outras épocas. Postula que toda

\footnotetext{
1. Este artigo retoma algumas idéias desenvolvidas nos capítulos 7 e seguintes de Internet, multimedia: $O$ que isso muda na realidade? INRP. Paris, 2000, cuja tradução $\mathrm{cm}$ espanhol está em curso nas ediçōes do Instituto Latinoamericano de Comunicação Educativa, ILCE, Calle Del Puente 22, Del. Tlalpam, México D.F., México. A tradução do francês para o espanhol (base da qual partimos) foi realizada por Luís Ignácio Sierra G.

2. Next Gringrich, "speaker" (presidente) da Câmara de Representantes dos Estados Unidos, To renew America, Harper Collins, New York, 1995.

3. Bill Gates, presidente da Microsoft, The road Ahead (A estrada à frente) Viking. New York, 1995.

4. WOLTON, D. Les fausses promesses de la societé Internet. (As falsas promessas da sociedade Internet.) Le Monde Diplomatique. Paris, junho, 1999.

5. Inclusive na vontade de uma universidade virtual latino-americana. (http://www.funredes.org/mistica/castellano/ ciberoteca/participantes/docupart/esp-doc-03.html)
} 
solução reside no progresso tecnológico e no desenvolvimento das redes.

A rede converteu-se em um dos paradigmas fundamentais do pensamento contemporâneo, da mesma forma que a comunicação, a qual se associa sistematicamente a este.

Assistimos a uma tripla crise: a do discurso religioso, a do discurso político e a do discurso científico, todos incapazes de proporcionar marcos explicativos coerentes ao cidadão do século XXI. Pois nem Deus, nem o poder político, nem os cientistas são suficientes para dar um sentido às nossas sociedades, nem para proporcionar uma explicação a suas crises sucessivas, nem para fixar metas, desafios, ideais claros. Daí por diante se opta por um novo discurso explicativo, no qual toda transcendência é de ordem tecnológica: só a técnica permite explicar e achar soluções para os problemas atuais.

Desse modo a técnica, os computadores, as redes, a Internet, ou a sociedade da informação são consideradas como as únicas respostas às questões de formação, de emprego, de democracia, de progresso em nossas sociedades.

\section{O desenvolvimento das redes}

converteu-se na suposta solução para os problemas de violência, de educação, de saúde, de desenvolvimento, de emprego e no suposto remédio para as desigualdades de todo tipo.
Os discursos sobre o futuro de nossas sociedades, em vez de estruturar-se a partir de ideologias políticas, invocam de agora em diante a técnica como solução para os problemas sociais e, inclusive, individuais. De uma utopia fundada sobre a transcendência (o discurso religioso), o social ou o conceito de progresso (o discurso político tradicional) passa-se a uma utopia fundada na técnica (a ideologia das redes). Os outros discursos explicativos, por sua parte, ficaram mudos ${ }^{6}$.

Neste contexto, a empresa e a comunicação transformaram-se nos dois conceitos fundamentais sobre os quais se pretende conceber a nova racionalidade da organização social.

Primeiro, pretende-se que a organização a partir do modelo da empresa (com as eventuais privatizações que a acompanham) é a única organização racional e rentável. A partir desta premissa, tudo, inclusive a educação, deve seguir esse modelo.

No mesmo sentido, afirma-se que a tecnologia é a única dimensão capaz de instaurar uma racionalidade nas empresas, nos serviços e nas organizações em geral. Esta dupla impostura leva a confundir informação e rentabilidade, informação $e$ racionalidade dos comportamentos, tecnologia e saúde, no terreno da saúde, ou informações e conhecimento, no terreno da educação.

A técnica é apresentada como imprescindível já que é mais rápida que o homem, possui mais memória e um maior poder de cálculo, além de neutralizar os problemas de espaço e tempo. Segundo

6. MATTELART. A. La communication monde. (A comunicação-mundo) Paris: La Découverte, 1999. 
esta ideologia, a panóplia tecnológica nos conduzirá a um estado ideal, à eficácia total, a um mundo sem conflitos, finalmente bem ajustado e racional, como se tal estado fosse possível.

Neste esquema ficam incluídas a educação e a universidade, ambas em busca de um modelo e de soluções às suas crises.

Sob o reino deste pensamento dominante, resulta politicamente incorreto colocar questões de sentido comum. Por exemplo, já não se pode perguntar se a globalização dos mercados financeiros internacionais (produto da convergência tecnológica), a qual teve e tem efeitos positivos para uma pequena parte da humanidade, não agudiza as crises monetárias e econômicas dos países do Sul. Igualmente, não se pode perguntar se, num nível local, realmente a compra de microcomputadores ou de softwares é o melhor investimento para se alcançar uma igualdade entre os alunos. Da mesma forma, parece estranho perguntar em que e sob quais condições, a conexão à Internet vai melhorar uma atividade, seja a do docente, do médico ou do cidadão. Estas são questões que correm o risco de parecerem absolutamente retrógradas.

Não obstante, parece-nos que as tecnologias de informação e a comunicação não são em si e por si uma panacéia.

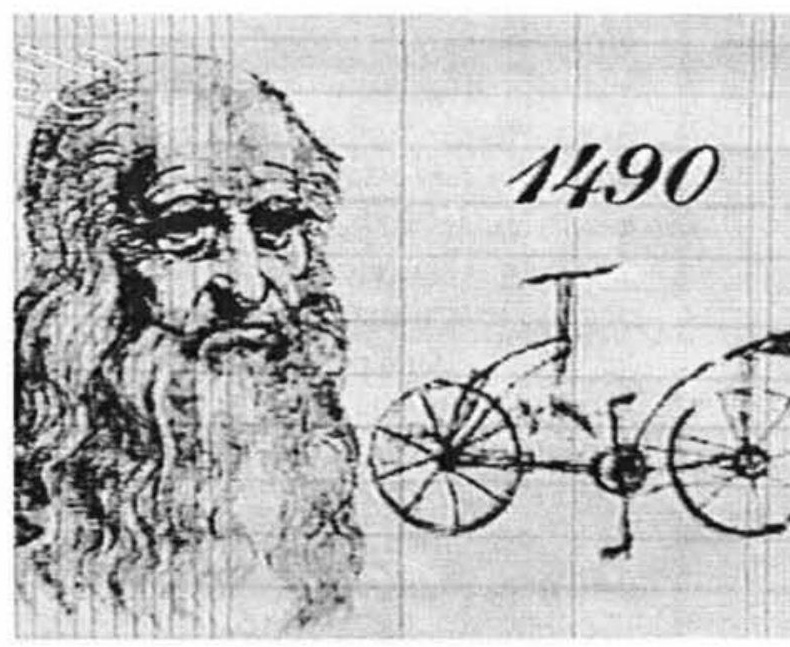

\section{TECNOLOGIAS DE INFORMAÇÃO E COMUNICAÇÃO E ACESSO AO SABER $^{7}$}

Ter acesso à informação não implica saber utilizá-la. O fato de entrar em uma biblioteca não significa saber procurar o livro de que se precisa, lê-lo e utilizá-lo. $\mathrm{O}$ valor de qualquer tecnologia deve ser calculado a partir da realidade, do que acontece no concreto, e não tendo como referencial aquilo que elas possibilitam potencialmente. A circulação interativa de informações de computador a computador, de rede a rede, tecnicamente possível, não implica uma interatividade criativa. A existência de programas que permitam compartilhar o trabalho também não cria uma inteligência coletiva ${ }^{8}$, nem

7. Sobre este assunto são importantes os seguintes documentos: DE SELYS, G. Le multimedia, marché du XXe. siècle. (A multimídia, caminhada do século XX) Le Monde Diplomatique, junho de 1998, p. 14-15.

Rapport des experts de haut niveau sur la societé de l'information. (Relatório dos especialistas de alto nível sobre a sociedade da informação.) ISPO, abril, 1997, Bruxelas.

Rapport sur l'enseignement superieur ouvert et à distance dans la Communauté Éuropéenne. (Relatório sobre o ensino superior aberto e a distância na Comunidade Européia.) Séc. (91) 388 final, 24, maio de 1991.

Mémorandum sur l'apprentisage ouvert e à distance dans la Communauté éuropéene. (Memorando sobre a aprendizagem aberta e a distância na Comunidade Européia.) Com (91) 388 final, 12 de novembro 1991.

L'Europe et la Societé de I'information planetaire. (A Europa e a sociedade da informação planetária) CD-84-94290-FR-C. 26 maio 1994.

8. Ver por exemplo as obras de Pierre Lévy. 
uma comunidade virtual, se comunidade significa grupo de atuantes com os mesmos interesses, que agem na mesma direção. A presença da máquina não implica a existência de tal comunidade.

Assim, a existência de um banco de dados não leva ao acesso ou ao manejo destes dados, nem à posse de um saber real. Neste sentido, o fato de pôr alguém diante de um teclado que possa dar-lhe acesso a um arquivo informatizado de biblioteca, não significa que esse alguém possua determinado saber.

O caminho que leva da conexão ao saber é longo e implica fenômenos sociais, psicológicos, jurídicos, econômicos, cognitivos e tecnológicos.

Os discursos utópicos sobre inteligência coletiva e a cibercultura pressupõem que uma parte da tecnologia, a que se refere às redes e ao hipertexto, irá determinar por si só o funcionamento dos demais campos da realidade.

Ditos discursos julgam o mundo segundo o que tecnicamente (e teoricamente) permitem as redes. Os arautos da inteligência coletiva ${ }^{9}$ supõem que a realidade deve adaptar-se às redes, como se as estruturas sociais, psicológicas, mentais, os modos de pensar, de aprender, de viver, de acreditar, de se representar os homens fossem só superestruturas que dependes- sem, de forma mecânica, de uma infraestrutura técnica.

\section{EXCLUSÃO DA DIMENSÃO SOCIAL}

As tecnologias de informação e de comunicação não propõem soluções ao desenvolvimento de nossa sociedade individual de massa. Vivemos em uma sociedade individual, na medida em que o ator social, busca, cada vez mais, a realização do indivíduo e não a realização de objetivos coletivos. Mas também vivemos em uma sociedade de massas ${ }^{10}$. Desde começos do século XX, e mais exatamente há uns cinqüenta anos, o progresso da democracia no plano político e a industrialização progressiva de todas as atividades (entre elas, as atividades culturais, em um primeiro momento e, atualmente, as de educação e formação) têm transformado a cultura e a educação em fenômenos massivos submetidos à lei do mercado.

$\mathrm{O}$ modelo do câmpus universitário virtual se preconiza como remédio às crises da universidade, mas deixa sem resposta muitas interrogações. A primeira se refere à função de socialização.

No sistema tradicional, um aprendizado se realiza através de um trabalho em grupo, apoiado no intercâmbio entre um professor e estudantes ou alunos e entre estudantes ou alunos entre si. Quando o câmpus virtual se dirige aos estudantes, dirige-se a indivíduos isolados, atomizados, em suas casas ou em seus lugares de trabalho sem oferecer-lhes necessariamente a possibilidade de reunirse de vez em quando.

Deste modo, um câmpus virtual, embora ofereça as melhores estratégias de cons-

9. Como Pierre Levy.

10. ORTEGA Y GASSET, J. La rebelión de las masas. (A rebeliāo das massas) Madrid: Espasa, 1937. 
trução de saberes, a partir das teorias pedagógicas, melhor adaptadas, encontra-se com freqüência ante o impasse de não poder desenvolver as capacidades de reflexão crítica do estudante, porque considera unicamente o aspecto pragmático da questão, ou seja, a transmissão de informações. $\mathrm{O}$ desenvolvimento da função analítica é possível graças às interações entre um grupo $\mathrm{e}$ um ou vários professores, mediante discussões, debates e análises realizados conjuntamente. Durante esses intercâmbios estruturados, poder-se-á dar ênfase ao desenvolvimento do espírito crítico, ao sentido rigoroso da argumentação e à análise. O trabalho a distância, em casa, frente a uma tela e um teclado, não permite esses intercâmbios e a orientação do professor pela via eletrônica não consegue substituílos. Igualmente existe o risco de formar estudantes menos socializados, menos críticos, ainda que eles sejam, à primeira vista, mais eficazes na ação concreta.

No plano internacional, a desigualdade tecnológica aumenta cada vez mais. Devemos lembrar que, enquanto a Califórnia, nos EUA, gasta $400 \mathrm{mi}$ lhões de dólares substituindo os computadores de seu sistema escolar, em todo o Chade ${ }^{11}$ só existem nove velhos PCs. Quando estes dois países respectivamente dobrarem, triplicarem ou centuplicarem seu material e, inclusive, se os programas de cooperação puderem centuplicar o estoque informático chadeano, a diferença entre eles será cada vez maior ${ }^{12}$.
Assim, constrói-se um mundo no qual a brecha entre os inforicos e os infopobres aumenta a cada dia, tanto entre os países do Norte quanto os do Sul, como também dentro de cada país. Esta brecha separa aqueles que têm acesso às tecnologias, sabem e podem tirar proveito delas, da imensa maioria excluída deste tipo de práticas.

Lembremos que ainda em 1995, 15\% da população possuía $75 \%$ das linhas telefônicas do mundo inteiro, e que a maioria desta minoria se encontrava nos Estados Unidos.

Neste quadro de desigualdades, a tecnologia constitui um elemento decisivo quando se trata de definir o lugar e o papel do Estado, com finalidades diferentes nos Estados Unidos e na Europa.

Nos Estados Unidos, por exemplo, as leis tentam impedir a criação de monopólios, e os abusos que derivam deles. Por exemplo, o poder federal abriu um processo contra a Microsoft para acabar com o seu monopólio ${ }^{13}$.

A política da União Européia aconselha um serviço universal. Alguns Estados nacionais estão considerando a possibilidade

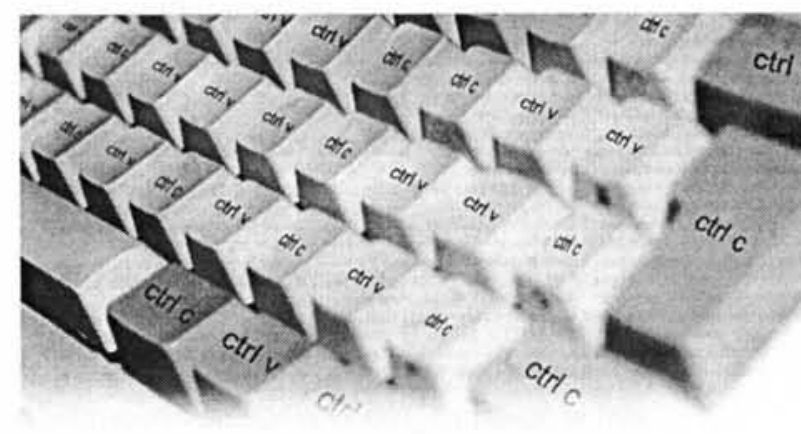

11. UNESCO, Revista Fontes. Junho, 1998.

12. NYE, Joseph, antigo responsável pelo Pentágono e Decano em Harvard (America's Information Edge. - Limites da informaçāo na América) Foreing Affairs. março, 1996 - estima que os equilíbrios geopolíticos se definem, daqui em diante, a partir de meios de controle do poder imaterial (soft power), e que esta situação manterá a supremacia mundial dos Estados Unidos.

13. Objetivamente, o referido processo nāo trouxe, até o momento, qualquer mudança na atuação da Microsoft. (N. Ed.) 
de garantir às populações desfavorecidas ou isoladas (parcialmente inválidas, de zonas rurais, populações mais pobres) $\mathrm{o}$ acesso $\mathrm{e}$ a conexão à rede.

Num nível local, e já não internacional, a tecnologia apresenta as desigualdades existentes. Ao observar uma escola, uma aula ou grupos de alunos, constatase que a tecnologia, só pela sua existência, não permite estabelecer qualquer tipo de igualdade.

$\mathrm{O}$ acesso à rede, à investigação, à leitura e à utilização de documentos multimídia exigem competências múltiplas, que aqueles que têm acesso à tecnologia, fora da escola, já possuem: uso do teclado, do mouse, da interface; familiaridade com a investigação através do diálogo homem-máquina; manejo dos sistema simbólicos (alfabeto, ícones...), faculdade de distinguir o real do virtual, a simulação da verdade.

\section{MUDANÇAS CONCEITUAIS}

As mudanças que se operam atualmente na educação, na universidade e na formação profissional, fazem parte da industrialização generalizada das atividades humanas, a qual comporta a passagem de uma atividade organizada ao redor de interações (entre seres humanos, nas aulas, nas escolas) a uma atividade industrial organizada em escala internacional ao redor de máquinas, e graças a elas.

A mudança da agricultura tradicional em indústria agroalimentária, ao longo do século XX, pode considerar-se, guardadas todas as proporções, como uma transformação do mesmo tipo. Tal mudança teve conseqüências econômicas, humanas e industriais incalculáveis.
Modificou tanto a geografia humana (desaparição de empregos no campo, êxodo rural, criação de megalópolis) como os modos de alimentação dos indivíduos. A mudança das produções culturais e educativas têm consequiências muito diversas, tais como a massificação, a industrialização, a alienação maior com relação ao capital.

Passa-se a falar em produtos educativos e culturais. A produção muda do ponto de vista da quantidade, assim como do ponto de vista da natureza mesma da produção, de tal modo que o público, que se tem convertido em consumidor, tem cada vez menos possibilidades de escolha. A indústria do disco, a da televisão, a do cinema, assim como a da educação modificam profundamente as atividades culturais. Seu objetivo não consiste em satisfazer as elites, mas em difundir seus produtos de maneira massiva. É assim que, contrariamente às expectativas de muitos, a industrialização não favorece, $a$ priori, a diversificação dos produtos, mas sim sua massificação.

Um maior número de redes de televisão, de programas de rádio, de livros impressos, de filmes produzidos não aumenta automaticamente as opções para o público
televidente ou leitor.

A liberação das ondas, com fins monopolistas de estado, também não tem suscitado uma real diversificação dos 
programas. Pelo contrário, provocou uma uniformidade do conjunto dos programas, os quais devem garantir, através da publicidade, a rentabilidade das redes.

$\mathrm{O}$ aficionado (que atuava, escolhia e tinha gostos) converteu-se em um simples consumidor, como o aluno cujos pais compram CDs pedagógicos no supermercado. Em um primeiro momento, o público, ao qual se dirigem os produtos, se massifica. O espectador, o leitor convertem-se, primeiro, em uma audiência que é preciso captar. Em um segundo momento, o industrial vai lhe propor outra gama de produtos: trata-se então de seduzi-lo. Falando em televisão, as redes temáticas, concebidas a partir de uma segmentação do mercado, não poderão continuar tendo as ambições culturais, sem rentabilidade, que tinham durante o antigo serviço público dos Estados nacionais.

A universidade norte-americana é concebida como uma empresa, na qual o ensino superior a distância deve vender seus produtos em um mercado (o da formação continuada, principalmente) regido pela lei da oferta e da procura ${ }^{14}$.

Os estudantes são naturalmente clientes e os cursos transformam-se em mercadorias. Uma universidade em competição permanente deve funcionar a partir de estratégias que lhe permitam ampliar o alcance, o impacto e aplicações do aprendizado aberto e a distância, para continuar sendo competitiva no mercado. Para isso precisa de estruturas de educação concebidas, antes de mais nada, a partir da demanda dos fregueses e não dos conteúdos propostos pelos professo- res. Assim, aparece a competição entre prestadores de serviços do aprendizado a distância.

Esta focalização, a partir do mercado, impõe à universidade a procura de freguesia para financiar o conjunto. Porém, um câmpus virtual resulta caro e é preciso rentabilizá-lo.

Em termos de lógica econômica se impõe a supremacia da lei do mercado. A lógica industrial identifica uma freguesia solvente, fabrica um produto que a satisfaça e vende-o rapidamente.

O produto tem uma validade limitada, depois da qual é substituído por outro, reiniciando deste modo o processo, trate-se de veículos, de máquinas de lavar, de discos, de livros, de programas de televisão, de cinema ou de diplomas.

Esta lógica busca igualmente reger o mundo da educação e a formação. Aparecem grupos internacionais suficientemente poderosos para organizar a difusão internacional de produtos de educação e formação. Os que possuem o controle da indústria da informática e o das telecomunicações, controlam igualmente a indústria do disco, a do cinema, a indústria da televisão e a do audiovisual. No campo da educação e da formação, os consórcios estão também na ordem do dia.

14. Um ponto de partida em espanhol para refletir sobre estes problemas pode encontrar-se no endereço htpp:// udgserv.cencar. udg. $\mathrm{mx} /$-cecad/weecad/1-96.htm\#al.I 
Em termos de processos de fabricação, aparece uma nova divisão do trabalho ${ }^{15}$. Esta taylorização dos processos de produção afeta o ensino, em uma cadeia que vai desde a concepção à distribuição, passando pelo marketing e fabricação. $\mathrm{O}$ autor de uma obra, o criador artístico, aquele que concebe um curso, converte-se em provedor de conteúdos.

\section{SUPREMACIA DAS MÁQUINAS E DOS CUSTOS}

Ao longo da história da humanidade, cada vez que o homem criou uma ferramenta, esta tendeu à automatização, para cumprir sozinha as funções às quais estava destinada. A máquina se encarregou aos poucos de realizar as tarefas antes realizadas pelo homem. Neste sentido, podemos falar de externalização.

Não obstante, é importante saber quando a externalização permite liberar-se de tarefas inúteis e enfadonhas, o que é positivo, e quando significa perda da posse de si mesmo, perda da identidade, crescimento do desemprego.

Individualmente, no caso de diferentes ofícios ou grêmios, a identidade profissional dependia da execução de certas tarefas, as quais foram, pouco a pouco, desaparecendo. As informações definiam certos lugares (bibliotecas, escolas) e certas funções (bibliotecários e mestres). Pois bem, estas informações vão se encontrar em outra parte, vão externalizar-se. Nas instituições, a função informática tornou-se tão importante que, constantemente, a organização não pode, ela só, assumi-la, e vê-se na necessidade de chamar atores externos para se ocuparem dela. Em que se convertem os antigos profissionais?

Todo o mundo sente a necessidade de equipar-se ante o duplo imperativo de aprender por toda a vida e de usar a rede para aprender. Assim, os indivíduos pensam que têm de se preparar por conta própria. O estudante, o professor, o trabalhador, o executivo, últimos elementos da cadeia, passam então a assumir os custos do seu material informático, servindo, ao mesmo tempo, aos interesses do Estado ou aos das empresas (as quais não têm que integrar esses custos no seu orçamento) e aos da indústria (para a qual se abrem novos mercados, forçosamente). Os interesses de políticos e industriais coincidem neste ponto ${ }^{16}$. Naturalmente, depois dos computadores, é preciso comprar programas, conexões, formações...

\section{MUDANÇAS DAS ATIVIDADES LABORAIS}

Aquilo que os alunos aprenderam mudou radicalmente, porque a maior parte dos ofícios mudou, e com eles, a noção mesma do trabalho. Nos países desenvolvidos, trabalhar significará, cada vez mais, comunicar-se com os demais, elaborar projetos comuns, realizá-los e, sobretudo, tentar produzir informação. Isto afeta tanto os ofícios de baixa qualificação, grande parte dos quais está em vias de desaparição, quanto os ofícios de alta qualificação. Nos países do Norte, as antigas cadeias de fabricação de automóveis, nas quais trabalhavam operários especializados, sem 
poder separar-se um instante das máquinas, cedem lugar a cadeias automatizadas, sem operários, cuja atividade humana consiste em controlar em uma tela a boa execução do trabalho, utilizando, se necessário, um programa automático de pesquisa de dados, prejuízos e reparações.

Às gerações de hoje, que assistem a esta mudança radical, se lhes impõe uma nova necessidade, na medida em que a renovação dos ofícios se acelera: saber mudar de ofício. Daí a expressão aprender a aprender utilizada com freqüência para designar o que os sistemas escolar, universitário e de formação devem realizar para preparar, não tanto para a execução de tarefas repetitivas, mas para mudanças profissionais sucessivas e requalificações periódicas.

\section{APRENDIZADO OU ADESTRAMENTO?}

Neste sentido, para que pode servir a tecnologia para educação? Para adquirir uma metodologia de pesquisa ou para limitar-se à repetição de gestos automáticos, sempre os mesmos?

As redes podem ser úteis ao aprendizado de busca de informação, do ponto de vista metodológico (tomo consciência de que, diante de uma situação, diante de qualquer problema, devo procurar uma solução idônea, a partir das informações que vou recolher, tratar e transformar), mas também do ponto de vista de procedimentos (aprendo que, para encontrar na Internet informações sobre um tema específico, devo utilizar tal programa, formular minha pergunta com operadores booleanos, dar uma determinada combinação de toques no teclado etc.).
Estes dois níveis estão intimamente unidos em toda busca de informação. É um imperativo saber com precisão o que se procura e por quê. Isto supõe uma atitude cognitiva particular, uma autonomia frente à máquina $\mathrm{e}$ às sugestões permanentes das interfaces, além de uma curiosidade permanente. Porém, é preciso conhecer igualmente as operações concretas que permitem realizar, inclusive, pesquisa mais simples. Só o equilíbr entre estas duas necessidades garante : eficácia de toda procura.

Não obstante, nenhuma das duas está exclusivamente ligada a um processo de aprendizado.

O manejo do computador e o das redes se adquirem igualmente, se não melhor, através de jogos de vídeo, ou seja, através de uma utilização lúdica das redes.

Por outro lado, o processo de busca de informação tanto mais se consolida quanto mais se pesquisa em bibliotecas ou em centros de documentação.

Se considerarmos o aprendizado deste ponto de vista do seu aspecto processual e tomando em conta a fascinação tecnológica de que falamos anteriormente, existe o risco de não só perdermos um tempo precioso, mas além de tudo de suscitar representações enganosas da aprendizagem.

O risco é duplo. O primeiro é uma valoração excessiva do aspecta puramente procedimental, o qual é ao mesmo tempo repetitivo (o que dá uma falsa segu- 
rança ao usuário) e aleatório, já que pode mudar na medida do ambiente tecnológico. A causa dessa atitude é, com freqüência, a fascinação que produz o aspecto mais superficial da técnica, a interface e a ideologia tecnicista. A máquina, incluindo seus aspectos mais superficiais e efêmeros, se diviniza, em prejuízo dos verdadeiros aprendizados metodológicos.

O segundo risco é desconhecer que um processo de pesquisa e de tratamento de informações não se limita exclusivamente à informática.

As redes têm os seus limites e isso também acontece com o hipertexto e a leitura na tela. $\mathrm{O}$ texto escrito, o audiovisual, as entrevistas de trabalho de campo são insubstituíveis na : construção do conhecimento.

É fundamental continuar recorrendo a fontes diversificadas de informação, tanto mais quando os meios e as tecnologias condicionam o exercício da atividade puramente humana de busca, de tratamento e de produção da informação. Entre a máquina e as formas do saber existem distintas relações. As condições para exercer a inteligência estão efetivamente ligadas às maneiras de representar, de codificar, às considerações da memória, ao espaço e ao tempo próprio da máquina. É assim que podemos nos perguntar quais são as relações que existem entre a máquina $\mathrm{e}$ já não o aprendizado, mas a transmissão de uma cultura.

\section{LEITURA E TEMPORALIDADE}

A partir do momento em que a leitura deixa de ser só a leitura do livro, uma das atividades centrais ao redor da qual se estruturava o sistema educativo, ela muda de natureza. A mudança de objeto apresenta vários tipos de problemas relacionados com o trabalho do professor e sua identidade profissional.

Cada uma das mudanças dos suportes, do volume (espécie de rolo) ao codex ou códice (folhas ligadas), e do manuscrito ao livro impresso, transformou, à sua maneira, os modos de indexação (modo de fazer índices alfabéticos e outros) e da leitura. O codex permitiu novos modos de indexar, de orientar-se, de arquivar, o que anteriormente não era possível com o volume. $\mathrm{O}$ livro impresso mudou o regime jurídico da propriedade do texto, democratizou sua posse, autorizou sua circulação, abriu novos tipos de redes de circulação (as livrarias, as universidades, os vendedores ambulantes) muito limitadas até o século XVI.

Atualmente se operam estes dois tipos de transformação a partir da passagem do material impresso ao hipertexto e à desmaterialização do texto. Aliás, os ofícios cuja prática girava em torno do livro também estão mudando.

Dentro dos sistemas de ensino, do ponto de vista de sua organização e de sua prática cotidiana até à introdução dos computadores nas aulas, produz-se um choque entre diferentes tempos. Já existia o choque entre tempo biológico (fome, cansaço) e tempo social (os recreios, o ritmo dos cursos). Agora, é preciso que se remaneje também o choque de temporalidade entre o tempo pedagógico (o de 
aprendizagem) e o tempo informático, (o da rede, a sucessão das diferentes telas, às vezes lenta demais, às vezes muito rápida). A rapidez de acesso à rede se opõe ao processo do aprendizado, o qual se inscreve em um tempo mais longo, um amadurecimento, tanto dos procedimentos da aprendizagem quanto das aprendizagens mesmas.

\section{Ora, a rede não conhece o} tempo do amadurecimento. $\mathrm{O}$ espaço e o tempo impostos pelas máquinas são muito diferentes do espaço e do tempo da aprendizagem clássica.

\section{TRANSMISSÃO DA CULTURA FRENTE ÀS REDES INFORMÁTICAS}

É sabido que os sistemas educativos permitem, fundamentalmente, a apropriação de sistemas de códigos, de estruturas organizacionais e de sistemas retóricos. Estes três elementos constituem ao mesmo tempo as condições da transmissão da cultura de uma sociedade e objeto da transmissão ${ }^{17}$.

Sem o manejo de um mínimo de códigos (a língua, a escrita, a oral, a imagem), não há ensino possível, pois este manejo é uma condição da recepção do ensino.
Da mesma maneira, se não se integram umas estruturas sociais (papel do professor, organização do tempo, do espaço...), também não há ensino possível. O papel do professor consiste em integrar os alunos a estas estruturas. Não há educação se não se explicam as figuras retóricas que permitem, por exemplo, passar do exemplo concreto à lei abstrata através de um movimento de indução ou, inversamente, da lei abstrata e geral às aplicações concretas. É o professor quem indica estes processos aos alunos.

A transmissão da cultura, do ponto de vista antropológico, é o conjunto de processos que permitem a inserção de gerações sucessivas na sociedade que as viu nascer. Ela é um longo processo de propagação dos sistemas de representação e de matrizes de representações da realidade que garantem a continuidade do grupo social.

A transmissão da cultura é lenta e se apóia em processos coletivos. Esta transmissão só se pode efetuar através de estruturas sociais permanentes que garantem dispositivos duráveis. Mas então, como realizar a transmissão da cultura através das redes? Uma universidade como a de Vancouver, que exporta seus diplomas massivamente com destino à América Latina, utilizando por exemplo a rede da Universidade Tecnológica de Monterrey, no México $^{18}$, enfrenta este problema ${ }^{19}$.

\section{QUESTIONANDO O SISTEMA}

Toda transmissão apóia-se, ao mesmo tempo, em uma in-formação (o fato

17. OLIVIER, Bruno. Observer la communication. Naissance d'une interdiscipline. (Observar a comunicação. Nascimento de uma interdisciplina) Paris: CNPS édition, 2000.

18. htpp://cerebro.cem.tesn.mx/

19. Ver por exemplo http:/itesm.estudies.abc.ca/info/social.html. 
de dar uma forma ao conteúdo transmitido, forma que depende do suporte que se escolhe), e em modos de organização (uma estrutura social no quadro da qual se decide a transmissão, seja qual for a sua natureza).

A forma atual do ensino caminha paralelamente ao estatuto dos professores, da existência da aula, de um certo manejar do tempo, de edifícios específicos, das bibliotecas, dos cadernos, dos livros...

A orientação, a aprendizagem centrada no estudante, a escola extramuros, a universidade virtual, a biblioteca virtual, o trabalho sobre o programa didático ou o livro eletrônico questionam, cada um a sua maneira, todos estes elementos do aprendizado.

A transmissão da cultura apóia-se no que os antropólogos chamam: a) um componente material (ferramentas técnicas de produção, bens de consumo); b) um componente social (o conjunto de relações sociais que the permitem instalar-se no tempo) e c) um componente simbólico (crenças, representações e mitos).

O componente material do sistema educativo muda sempre, já que as máquinas ocupam um lugar cada vez mais importante. O componente social muda também, dado que a relação do grupo com o professor e dos membros do grupo entre si pode desaparecer. O componente simbólico se transforma completamente. A relação com o saber se fundou, durante séculos, na cultura ocidental, sobre valores que têm a ver simultaneamente com o plano social (a situação na sociedade da pessoa que sabe), com o plano epistemológico (a situação na sociedade do conhecimento), com o plano moral (forma que toma a passagem da ignorância ao conhecimento) e com o plano discursivo (forma que toma um discurso de conhecimento). Entre estes valores destacamos:

- O respeito à autoridade (o professor possui o conhecimento, assimilado à informação, razão pela qual é respeitado);

- A busca de continuidades, ao mesmo tempo que uma busca de compartimentação segundo as disciplinas (a disciplina é um corpo constituído sem vazios, sem espaço em branco, e o saber está formado de disciplinas coerentes em si mesmas e entre elas);

- A fixação das relações de causa e efeito (uma causa produz um efeito);

- A transparência da linguagem utilizada para explicar (a metalinguagem não atrapalha a descrição);

- A exigência de certeza (onde se instala a incerteza não existe o conhecimento);

- A necessidade de simplificar (o que se concebe bem, se enuncia claramente);

- A impossibilidade de confundir realidade com representação, ação simulada e ação real (desde o princípio $o$ trabalho não é brincar, até o eterno juízo a televisão não é importante ${ }^{20}$ ); 
- A idéia de que o saber se consegue graças a um esforço.

Cada um desses valores está fortemente questionado pela tecnologia na escola, na aula e na universidade, já que a máquina para comunicar é algo mais que um acessório suplementar na aula. Ela questiona os princípios e os valores tradicionais do setor educativo.

A profissão muda e, com ela, o prestígio antigamente vinculado à apropriação de um saber, o qual agora parece poder comprar-se em supermercados, como um jogo de vídeo, sob o mesmo suporte e na mesma prateleira. Tudo isto vem, pois, a desestabilizar, a perturbar a profissão.

\section{OFÍCIO E IDENTIDADE}

Um ofício não é só um meio de ganhar a vida, é também uma atividade que outorga uma identidade ao sujeito social. Esta identidade depende do reconhecimento dos demais, como também do domínio de gestos profissionais e do que podemos chamar um território, o qual pode ser material ou simbólico.

Entendemos por território material o controle de espaços, de orçamentos, de máquinas.

O domínio sobre espaços concretos sempre existiu, como demonstram a chave do armário ou da sala de documentação e da sala de aulas. No plano mais concreto este domínio se expressa através de gestos como a posse de chaves que abrem portas, de cartões que dão acesso a certos espaços.

As redes criam novos tipos de territórios. O acesso a estes novos territórios está condicionado pela aquisição de modems, programas, computadores, linhas telefô- nicas, fluxos aceitáveis, palavras-chave que abrem o caminho em direção a dados ou redes.

O território material (uma sala, a duração do curso, um grupo de alunos ou de estudantes) e o território simbólico (o manejo de conceitos, direito de decidir sobre a organização do tempo e do espaço, posse de uma competência reconhecida pelos demais atores) cujo domínio era exercido pelo professor, deixam de operar quando o sistema educativo utiliza as redes, o que comporta hoje a aparição de outras chaves. A posse destas novas chaves implica outros processos.

As estruturas de comunicação que o professor manejava, e que ele mesmo organizava, são substituídas por modos de comunicação imprevisíveis, os quais ele já não controla.

Aquilo que acontece nas salas de aulas acontece também nas salas de documentação e nas bibliotecas. O documento eletrônico modifica as práticas profissionais, organizadas ao redor do armazenamento de livros (suporte papel), de sua localização, de sua classificação, de sua distribuição e da sua manutenção.

As transformações atuais indicam que se vai substituir o livro, objeto físico, palpável, localizável, por um conjunto de procedimentos. $\mathrm{O}$ livro, centro de numerosas exigências (respeito pelo texto, cuidado no manejo de livros, controles destinados a impedir roubos e danos), cede 
seu lugar a uma série de operações realizadas pelo usuário em um teclado, frente a uma tela. $O$ papel do documentarista ou da bibliotecária muda: passa a ajudar o usuário a formular suas demandas e a se orientar no labirinto das operações e procedimentos informáticos.

Tanto para o professor quanto para o profissional da documentação, as referências que the permitem exercer seu ofício, os territórios, os gestos profissionais, enfim, tudo o que fundamenta sua identidade profissional se vê mais ou menos modificado.

\section{CONCLUSÕES PROVISÓRIAS}

Na educação, usa-se o computador para a criação, a busca, a consulta e o intercâmbio de documentos e a organização de atividades a partir de programas de aprendizagem.

Cada uma destas atividades modifica as práticas e os territórios tradicionais da atividade educativa... A aula, a biblioteca ${ }^{21}$ não podem se contentar só com a consulta de documentos que devem ser apreendidos; agora elas criam também documentos, se abrem ao mundo, com a busca e intercâmbio de documentos, com outros cursos, por exemplo. Ou seja, o programa específico para um aprendizado, o programa didático, gera novas atividades.

As mudanças organizacionais serão importantes no que se refere à maneira de dominar uma aula, ao planejamento de outros cursos, à organização dos centros de documentação e dos estabelecimentos educativos em geral.
A ferramenta informática transforma os dados do trabalho e, por conseguinte, a identidade profissional de três maneiras:

- Permite manejar números grandes, em termos de cálculos e em termos de quantidade de informação que é preciso armanezar, distribuir ou explorar.

- Permite evitar tarefas enfadonhas e repetitivas, estabelecendo as condições necessárias para automatizá-las.

- Finalmente, dentro do quadro dos programas concebidos para este objetivo, pode converter-se em uma ajuda para a construção de conhecimentos, em particular graças aos programas de simulação ou aos programas de aprendizagem concebidos em uma perspectiva construtivista.

Uma vez bem definido para que serve a informática, resta precisar os campos nos quais

sua instalação leva a reestruturar os métodos e a organização do trabalho

na escola, como nos outros setores de atividade.

O primeiro ponto que deve ficar claroé o da escolha das tecnologias. Quais são úteis, e úteis para quem? Como organizar sua distribuição dentro do estabelecimento? Como prever a utilização das tecnologias? Quem tem acesso permanente aos postos de

21. CAPURRO, R. Cultura digital e información en el próximo milenio. (A cultura digital c informação no próximo milênio.) Contribuição ao $6^{\circ}$ Congresso Nacional de Bibliotecólogos e Documentalistas. Bogotá, Colômbia, 4-7 Julho ano 2000. htpp://v.hbi-stuttgart.de/-capurro/bogota.htm. 
trabalho e quais são os princípios da utilização? O segundo ponto surge a partir de uma nova maneira de contabilizar o tempo: o tempo de que precisa o professor para preparar seu trabalho muda, assim como o tempo para utilizar estes documentos.

No que diz respeito à organização do espaço escolar, é preciso reconsiderá-lo no seu conjunto. Algumas atividades poderão realizar-se dentro da aula ou do estabelecimento, enquanto outras implicam comunicação com outras entidades, políticas, empresariais, culturais etc. Além disso, poder-se-ão levar a cabo outras atividades com interlocutores mais distantes.

Se for possível buscar e facilitar uma apropriação real das instalações informáticas por parte dos professores e dos alunos, estas transformações não se podem manejar simplesmente a partir de ordens administrativas. É necessário imaginar uma certa forma de organização cooperativa na qual se associem as autoridades administrativas, as competências informáticas, no que diz respeito às redes e aos atores.

Trata-se de um verdadeiro plano reengineering (reestruturação), com consequiências a priori difíceis de calcular já que tudo isto afeta a identidade profissional dos atores, sua maneira de trabalhar e sua identidade (gestos profissionais cotidianos, modo de calcular o tempo de trabalho, competências específicas). Mais tarde ou mais cedo, se apresenta de maneira inevitável a questão do poder. Quem decide estas mudanças?

Já falamos dos estragos da ideologia tecnicista, a qual reduz os problemas sociais, humanos ou de aprendizado a dados técnicos. Muito freqüentemente, nas universidades e escolas, só se leva em con- ta a conexão às redes, a compra de equipamentos, sem considerar absolutamente as conseqüências que traz consigo $\mathrm{a}$ introdução da máquina. A nova situação apresenta certo número de perguntas à universidade, às quais ela deverá responder rapidamente, a partir de uma análise econômica, social e política dos desafios a curto prazo.

Dentro de um quadro regido cada vez menos por regras fixas no comércio internacional, os desafios mais importantes se referem à definição dos conteúdos, às modalidades de acesso à rede, à formação, às tarifas de conexão e ao modo de fixá-las, tomando em conta as poucas coisas que permanecem em pé frente às regras internacionais de comércio.

É possível identificar dois movimentos, cada um dos quais tem conseqüências diferentes.

$\mathrm{O}$ primeiro corresponde à tendência natural do capitalismo, quer dizer, a tendência a transformar toda a atividade humana em mercadoria vendável. Esta se combina com o movimento de industrialização, iniciado durante a primeira metade do século XX, o qual acelerou a chegada das tecnologias de informação e de comunicação.

A este movimento de mercantilização pode opor-se outro movimento, o de apropriação dos meios por parte de um movimento social e da sociedade civil, para utilizá-los segundo sua conveniência. 
Já se podem ver os primeiros rastros deste movimento em numerosos países, tanto no mundo desenvolvido como no Terceiro Mundo (durante a Reunião de Cúpula da OMC em Seattle, com as tentativas de utilizar a rede com fins não comerciais). Eles merecem ser observados com atenção ${ }^{22}$.

Resumo: $\mathrm{O}$ autor discute como as tecnologias de informação e comunicação tornaram-se base da ideologia da sociedade contemporânea, sendo apontados como solução para os principais problemas que se enfrentam: violência, desemprego, desenvolvimento, educação, saúde etc. Detém-se a pensar a relação entre as novas tecnologias e a educação, destacando a importância de se questionar o tipo de uso e os fundamentos das redes virtuais para a educação. Ele destaca que as redes virtuais de ensino a distância não são capazes de promover a interação crítica e reflexiva propiciada pela interação alunos-professor, correndo-se o risco de restringir-se o processo de formação à transmissão pragmática de informações. Destaca, ainda, as mudanças que se operam no mundo da educação no que diz respeito aos papéis do professor, do aluno, à função do livro e da cultura, bem como a relevância do uso das tecnologias pelo movimento social com fins realmente educativos.

Palavras-chave: tecnologia da informação, educação, universidade virtual, conhecimento, Internet
Qual será o papel da Internet no setor da educação? O mesmo sem dúvida que nos demais setores.

É de se temer que, se os atores sociais não se apropriarem da Internet, em certo prazo, esta servirá só para desenvolver atividades lucrativas e não fins realmente educativos.

\section{(Educational systems among machines and networks)}

Abstract. The author discusses how information and communication technologies became the base of contemporaneous society's ideology, being pointed to as the solution for the main problems that are being confronted: violence, unemployment, development, education, health, etc. It considers the relation there is between new technologies and education, highlighting the importance of questioning the type of use and the foundations of virtual networks for education. It emphasizes that virtual distance learning networks are incapable of promoting the critical and reflexive interaction the contact between students and teachers is able to stimulate, posing the risk of limiting the educational process to the pragmatic transmission of information. It also highlights the changes that have been taking place in education regarding the teacher and student roles, the function of the book and of culture, as well as the relevance of the social movement's use of technologies with actual educational goals.

Key words: information technology, education, virtual university, knowledge, Internet

22. Como ponto de partida para tais exploraçōes, pode se sugerir em particular htpp://www.funredes.org/mistica/ castellano/trabajo-social.html 